\title{
Análise da conformidade higiênico-sanitária de unidades agroindustriais familiares produtoras de derivados lácteos em municípios do Rio Grande do Sul
}

\author{
Claudia Maria Prudêncio de Mera \\ Universidade de Cruz Alta - Cruz Alta - RS - Brasil \\ ORCID: http://orcid.org/0000-0001-5293-3054 \\ Thomas Rosa Menegazzi \\ Universidade de Cruz Alta - Cruz Alta - RS - Brasil \\ ORCID: https://orcid.org/0000-0002-5435-3157 \\ Jorge Stumpfs Diaz \\ Universidade de Cruz Alta - Cruz Alta - RS - Brasil \\ ORCID: https://orcid.org/0000-0002-6530-2419
}

\section{Resumo}

O presente trabalho, de conteúdo quantitativo descritivo, buscou uma análise da conformidade higiênico-sanitária de agroindústrias familiares, produtoras de derivados lácteos, no Rio Grande do Sul. Nas unidades agroindustriais familiares, o controle da qualidade da produção acontece rotineiramente pelos proprietários, dessa forma, uma avaliação da conformidade de todo seu ciclo produtivo auxilia na redução de prejuízos, relacionados à saúde ou econômicos, agregando para o consumidor e para as agroindústrias um valor inestimável ao produto oriundo de todo esforço produtivo. Nesse contexto, foi aplicado um check list, dividido em 5 grupos, em 10 unidades agroindustriais, com o objetivo de quantificar as conformidades. Pela análise, a média de conformidade por grupo de estudo foi $47,18 \%$, e 55,03\% a média geral dos grupos. Ainda, na análise individual das agroindústrias, seguindo o critério de classificação do estabelecimento conforme seus itens atendidos, grupo 1 (76\%-100\%), grupo 2, (51-75\%), grupo 3 (0-50\%), nenhuma propriedade classificou-se no grupo 1, sete agroindústrias colocaram-se no grupo 2 e três no grupo 3. Diante desses resultados, melhorias organizacionais no interior das agroindústrias, instauração de programa de saúde dos trabalhadores, melhorias nas instalações, como as telas nas portas e adequação da climatização dos ambientes, programa de controle de matéria-prima, de qualidade do produto final e embalagens e, ainda, implementação de um programa documental de todas as atividades desenvolvidas, proporcionam a melhoria sanitária dos produtos, gerando maior segurança alimentar e credibilidade aos produtores. Palavras-chave: Agroindústria Familiar. Derivados Lácteos. Check List. Segurança Alimentar. 


\section{Analysis of the hygienic-sanitary conformity of agroindustrial units family producers of dairy derivatives in municipalities of do Rio Grande do Sul}

\section{Abstract}

The present work, with descriptive quantitative content, sought an analysis of hygienicsanitary compliance of family agroindustries, producers of dairy products, in Rio Grande do Sul. In family agroindustrial units, owners routinely carry out production quality control, so an assessment of the conformity of their entire production cycle helps to reduce losses, related to health or economic, to the consumer and to the agroindustries adds a value invaluable to the product coming from all productive effort. In this context, a check list was applied, divided into 5 groups, into 10 agroindustrial units with the purpose of quantifying the conformities. By the analysis, the mean compliance by study group was $47.18 \%$, and $55.03 \%$ was the overall mean of the groups. Still, in the individual analysis of the agroindustries, following the criterion of classification of the establishment according to its attended items, group 1 ( $76 \%-100 \%)$, group 2 (51-75\%), group $3(0-50 \%)$, no property was classified in group 1, seven agroindustries were placed in group 2 and three in group 3. In view of these results, organizational improvements within agroindustries, introduction of a workers' health program, improvements in facilities such as the screens at the doors and adaptation of the air conditioning of the environments, raw material control, final product quality and packaging, implementation of a documentary program of all the activities developed, provide the sanitary improvement of the products, generating greater food security and credibility to the producers.

Keywords: Family Agroindustry. Dairy Derivatives. Check list. Food Safety.

\section{Análisis del cumplimiento de normas higiénico-sanitario de las unidades agroindustriales familiares que producen productos lácteos en los municipios de do Rio Grande do Sul Resumen}

El presente trabajo, con contenido cuantitativo descriptivo, buscó un análisis del cumplimiento higiénico-sanitario de las agroindustrias familiares, productoras de productos lácteos, en Rio Grande do Sul. En las unidades agroindustriales familiares, el control de la calidad de la producción ocurre rutinariamente por los propietarios, de esta manera, una evaluación de la conformidad de todo su ciclo de producción ayuda a reducir las pérdidas relacionadas con la salud o la economía, agregando al consumidor y las agroindustrias un valor inestimable para el producto de todos los esfuerzos productivos. En este contexto, se aplicó una lista de verificación, dividida en 5 grupos, en 10 unidades agroindustriales, con el propósito de cuantificar las conformidades. Por análisis, el cumplimiento promedio por grupo de estudio fue $47.18 \%$, y $55.03 \%$ fue la media general de los grupos. Aún así, en el análisis individual de las agroindustrias, siguiendo el criterio de clasificación del establecimiento según sus ítems atendidos, grupo 1 (76-100\%), grupo 2 (51-75\%), grupo 3 (0$50 \%$ ), ninguna propiedad clasificada en el grupo 1, siete agroindustrias se ubicaron en el grupo 2 y tres en el grupo 3. En vista de estos resultados, las mejoras organizativas dentro de las agroindustrias, el establecimiento de un programa de salud para los trabajadores, las mejoras en instalaciones tales como las pantallas en las puertas y la adaptación del clima de los entornos, programa de control de la materia prima, la calidad del producto final y el empaque $y$, también, la implementación de un programa documental de todas las actividades desarrolladas, proporcionan el mejoramiento sanitario de los productos, generando mayor seguridad alimentaria y credibilidad para los productores.

Palabras clave: Agroindustria familiar. Derivados lácteos. Lista de verificación. Seguridad alimentaria. 


\title{
1 Introdução
}

Com o passar das décadas, a agricultura familiar desenvolveu peculiaridades em seu modo de transformar a matéria-prima produzida em seus estabelecimentos rurais, direcionando para a sua alimentação e para o mercado consumidor produtos diferenciados, adquirindo características sensoriais marcantes e muito apreciadas que contrastam com alimentos excessivamente industrializados, direcionados à produção em larga escala.

A implementação da agroindústria em uma pequena propriedade mantém a mão de obra familiar inserida no seu contexto, utilizando sua própria matéria-prima ou proveniente de comunidades próximas. Em decorrência de uma melhor utilização do potencial da propriedade, originam-se lucros oriundos de uma produção direta, sem intermediários. Nesse sentido, destaca-se o Decreto 49.341/2012, ao definir agroindústria:

\begin{abstract}
Agroindústria familiar: o empreendimento de propriedade ou posse de agricultor (es) familiar(es) sob gestão individual ou coletiva, localizado em área rural ou urbana, com a finalidade de beneficiar e/ou transformar matérias-primas provenientes de explorações agrícolas, pecuárias, pesqueiras, aquícolas, extrativistas e florestais, abrangendo desde os processos simples até os mais complexos, como operações físicas, químicas e/ou biológicas (RIO GRANDE DO SUL, 2012).
\end{abstract}

A aproximação das agroindústrias da matéria-prima descentraliza a produção, leva a uma redução dos custos de transporte e dependência de insumos externos, diminui migrações desordenadas, com isso esse modelo de desenvolvimento valoriza o meio ambiente e proporciona uma melhor utilização do espaço territorial (PREZOTTO, 2002). Do ponto de vista econômico, um produto com nível qualificado de inspeção recebe mais garantias de comercialização, tornando-se equivalente aos industrializados em larga escala, inserindo definitivamente a agroindústria familiar no mercado consumidor. Além disso, reduz mediadores, diminui as perdas nos ciclos produtivos, adiciona valor à transformação do produto na unidade familiar, possibilitando um preço constante de comercialização (ROCHA JUNIOR e CABRAL, 2016).

Em nível social, aproxima os habitantes de uma mesma região, mantendo tradições provenientes de interações sociais. Uma agroindústria bem estabelecida alicerça a sucessão familiar, motivando os jovens a investir esforços na produção e busca de conhecimentos aplicáveis nas próprias agroindústrias, propiciando um desenvolvimento local e regional da comunidade ou município no qual estão inseridos, reduzindo o êxodo do meio rural. Ainda sobre esse assunto, Albarello e Deponti destacam:

Analisar a cadeia agroindustrial familiar, na ótica da geração de crescimento/ desenvolvimento em uma determinada região do país é um desafio que exige levar em conta as competências laborais e de planejamento familiares, aliados à inovação e à tecnologia utilizada neste sistema produtivo agrário, sua viabilidade econômica, seus impactos no meio ambiente e seus efeitos na qualidade de vida dos habitantes da região em questão, sob o ponto de vista do desenvolvimento sustentável (ALBARELLO e DEPONTI, 2015). 
Diante desse cenário, é pertinente que uma agroindústria mantenha uma família gerando renda no campo, por menor que seja. Como consequência do desenvolvimento local e regional, distribui-se a renda para a população, comercializando produtos e gerando riqueza nacional (ROCHA JUNIOR e CABRAL, 2016).

Visto o impacto das agroindústrias na sua delimitação produtiva e territorial, serão estudadas unidades agroindustriais do Rio Grande do Sul, um grande produtor de derivados lácteos, tornando-se relevante o estudo da adequação higiênico-sanitária das agroindústrias, pois muitos consumidores apreciam seus produtos coloniais, analisando sua adequação higiênico-sanitária com base em um check list da Agência Nacional de Vigilância Sanitária (ANVISA). Esse check list é um instrumento importante porque tem origem legal, e é utilizado para avaliar e instituir alterações estruturais e conceituais pela definição de pontos em não conformidade, bem como aqueles que necessitam monitoramento constante para evitar contaminação direta e indireta dos alimentos, matéria-prima, embalagens e equipamentos.

Diante da importância de um diagnóstico situacional das agroindústrias, para posterior apresentação aos produtores dos pontos passíveis de melhorias, este artigo buscou avaliar se as agroindústrias lácteas apresentam adequação com relação à legislação utilizada, para análise das conformidades, identificando os setores estruturais e do processo produtivo das agroindústrias que desenvolvam riscos à segurança alimentar.

\section{Conceitos da agroindústria familiar}

Atualmente, diante da mudança de perspectiva da produção e distribuição de alimentos, os agricultores familiares assumem um papel significativo na diversificação produtiva, opondo-se às propriedades monocultoras ocupantes de grandes áreas territoriais. Conforme dados de 2006, do Instituto Brasileiro de Geografia e Estatística (IBGE), no Brasil 84\% das propriedades agropecuárias são provenientes da agricultura familiar, sendo que no Estado do Rio Grande do Sul esta representação é de $86 \%$. Torna-se evidente a significativa representatividade da agricultura familiar, contrastando a elevada participação da agricultura familiar com a pouca posse de terra (LANES, 2015).

Dados do $1^{\circ}$ trimestre de 2015 demonstram que a aquisição de leite por laticínios foi de 6,128 bilhões de litros no Brasil, evidenciando a grande produção na área de leite e derivados, incluindo-se aí as grandes indústrias e agroindústrias familiares, mas esse número por certo é maior, devido à marginalização de muitas agroindústrias familiares, que seguem na informalidade (ANDRADE et al., 2016). Nesse contexto, a importância de um laticínio de produção familiar, como segue na Cartilha da Agroindústria Familiar de Sgarbi et al.:

O processo de transformação da matéria-prima feita pelos próprios agricultores e suas famílias, favorece a superação da prática dos agricultores de produzir a matéria-prima e entregar para que terceiros a transformem e agreguem valor a ela. Trata-se de uma possibilidade de dinamizar economicamente o espaço rural, criar novos postos de trabalho e ofertar produtos diferenciados, feitos em pequena escala, onde a 
qualidade pode superar os padrões sanitários e engloba aspectos ambientais, sociais e culturais (SGARBI et al., 2007).

Os produtos coloniais familiares ganham cada vez mais visibilidade nacional, o que se verifica pelo marcante modo produtivo obtido pelas décadas de habitação nas comunidades rurais, algo que está fazendo a diferença no fornecimento de alimentos. Segundo Zuin e Zuin, é notável a importância desses produtos:

\begin{abstract}
E por assim ser é que estes produtos com história, até há poucos anos, considerados como símbolos do atraso socioeconômico de um indivíduo, de uma região ou de um país, vêm sendo reconhecidos, em primeiro lugar, pela União Europeia, como elementos potencialmente capazes de revitalizar a economia dos meios rurais. A busca dos consumidores pelos produtos com história faz com que paguem mais por eles, convertendo-a em um componente comercial do produto, o que legitima o argumento de que a tradição ajuda a vender, não só vendendo-o mais, mas, principalmente, a vender melhor (ZUIN e ZUIN, 2008, p.111).
\end{abstract}

No processamento artesanal de pequeno porte, os estabelecimentos caracterizam-se por serem dirigidos diretamente por agricultor (es) familiar (es) com meios de produção própria ou mediante contratos de parceria, cuja produção abranja desde o preparo da matéria-prima até o acabamento do produto, seja realizado com o trabalho predominantemente manual e que agregue aos produtos características peculiares, por processos de transformação diferenciados que lhes confiram identidade, geralmente relacionados a aspectos geográficos e históricos culturais locais ou regionais (RIO GRANDE DO SUL, 2012).

Mesmo com a extensa legislação vigente, existe uma grande dificuldade de adequação, e comunicação ao proprietário, de suas prioridades dentro da agroindústria, como em processos de comercialização e acesso aos mercados, inadequação de embalagens, instalações e tecnologia de produção e, primordialmente, no que se refere à qualidade desses produtos. A padronização, muitas vezes, requer investimentos em maquinário e infraestrutura, trazendo dificuldades para as classes menos favorecidas de agricultores (NICHELE e WAQUIL, 2011), porém pequenas mudanças utilizadas de maneira preventiva propiciam um maior controle do produto final.

\title{
3 Qualidade e gestão sanitária dos produtos
}

Muitas vezes, análises feitas por amostragem e suas metodologias não garantem o alimento final isento de microrganismos patogênicos, por isso surgem as medidas preventivas como maneira mais rápida, eficaz e menos onerosa para o proprietário, de modo que o questionário utilizado da Resolução Diretiva Colegiada (RDC $n^{\circ} 275$ ), caracterizando a padronização de Boas Práticas de Fabricação (BPF), pode ser um instrumento norteador e os métodos finais de controle sejam auxiliadores (FERREIRA et al., 2013). Corroborando a importância desse documento, utilizando o check list, Lanes e Siedenberg relatam:

A lista de verificação (check list) apresenta todos os pontos a serem observados para saber se o estabelecimento está em conformidade com as BPF, sendo utilizada nas inspeções sanitárias para: comunicação do 
início de fabricação de produto dispensado da obrigatoriedade de registro, inspeção programada, programas específicos de vigilância sanitária, reinspeção, renovação de licença sanitária, renovação de registro, solicitação de licença sanitária, solicitação de registro, verificação ou apuração de denúncia, além de outros motivos (LANES e SIEDENBERG, 2015).

São itens de verificação: áreas externas das instalações; acessos; pisos; tetos; paredes e divisórias; portas; janelas e outras aberturas; escadas e estruturas auxiliares; instalações sanitárias e vestiários; lavatórios; iluminação e instalação elétrica; higienização das instalações; controle integrado de vetores e pragas; abastecimento de água; manejo de resíduos; esgotamento sanitário; leiaute da infraestrutura para o adequado fluxo de produtos; equipamentos, móveis e utensílios (adequação funcional e higiênica); avaliação dos manipuladores (vestuário, hábitos higiênicos, estado de saúde); programas de controle de saúde do pessoal envolvido; utilização de equipamentos de proteção individual (EPI); programas de supervisão e capacitação dos colaboradores; produção e transporte dos alimentos, desde a matéria-prima até a embalagem; avaliação da adequação da rotulagem e armazenamento do produto final; existência de controle do produto finalizado; existência de documentação e cursos de boas práticas de fabricação, procedimentos operacionais padronizados (POPs); por fim, realiza-se a classificação do estabelecimento nos níveis de exigência sanitária (BRASIL, 2002). Nestes itens baseia-se a Lista de Verificação de Boas Práticas, abordando uma série significativa de tópicos que são subdivididos em um maior número de objetos de análise.

A norma RDC $n^{\circ}$ 275, de 21 de outubro de 2002, da Agência Nacional de Vigilância Sanitária, norteou a pesquisa com base em sua lista de verificação de boas práticas de fabricação. Levou-se em conta a diferenciação cultural do meio rural, por serem seus métodos agregadores de qualidade sensorial e a adaptabilidade dos produtores às mudanças com discussão de possibilidades e alterações, tanto estruturalmente como conceituais, otimizando os processos para obtenção de um produto com a ausência de perigos físicos, químicos e biológicos. A vigilância sanitária, empreendida no âmbito dos estabelecimentos que industrializam alimentos, garante a certeza de um alimento inócuo, sem microrganismos patogênicos, caracterizando-se como:

Entende-se por vigilância sanitária um conjunto de ações capaz de eliminar, diminuir ou prevenir riscos à saúde e de intervir nos problemas sanitários decorrentes do meio ambiente, da produção e circulação de bens e da prestação de serviços de interesse da saúde, abrangendo: I - o controle de bens de consumo que, direta ou indiretamente, se relacionem com a saúde, compreendidas todas as etapas e processos, da produção ao consumo; e II - o controle da prestação de serviços que se relacionam direta ou indiretamente com a saúde (BRASIL, 1990).

As Boas Práticas de Fabricação dos alimentos geram uma garantia de que estes foram manipulados com a intenção de evitar contaminação física, química e microbiológica, através de medidas rotineiras no processo produtivo, direcionadas pelas legislações vigentes. A regulamentação de âmbito federal do Ministério da Saúde é a Portaria da Secretaria de Vigilância Sanitária n 326/1997, e do Ministério da Agricultura e Abastecimento é a Portaria $n^{\circ} 368 / 1997$, que regulam sobre as 
condições higiênico-sanitárias e de boas práticas de elaboração para estabelecimentos elaboradores/industrializadores de alimentos, padronizando e direcionando os processos para produtos de origem animal.

Um curso de BPF deve abranger os seguintes tópicos: instalações, parede, pisos internos e externos, esgotamento industrial, janelas, teto, iluminação, instalação elétrica; pessoal, aparência, adornos, sanitização de mãos, uniforme, luvas, conduta higiênica; operações, recepção de matéria-prima, controle de estoque de matéria-prima, processamento, embalagem, armazenamento do produto final, produtos químicos; controle de pragas; registro e documentação; implementação de um manual. A descrição dos procedimentos de monitoramento e verificação das BPF é adotada sob a forma de POPs. Os procedimentos devem ter um formato uniforme, com título, objetivo, campo de aplicação e instruções de trabalho, frequência, observações, e são eles: higienização das instalações, equipamentos, móveis e utensílios; potabilidade da água; higiene e saúde dos manipuladores; manejo dos resíduos; manutenção preventiva e calibração dos equipamentos; controle integrado de vetores e pragas urbanas; seleção de matérias-primas, ingredientes e embalagens; e recall.

Segundo Silva (2017), microrganismos indicadores demonstram contaminação fecal, aqueles que ocasionam deterioração no processamento, armazenamento ou distribuição, causando distúrbios e doenças patogênicas. A origem de doenças transmitidas por alimentos tem como fontes de contaminação: más condições higiênico-sanitárias; matéria-prima contaminada; manipulação incorreta (refrigeração indevida, manipuladores doentes, armazenamento incorreto); contaminação cruzada (produtos não processados, utensílios e ambiente de trabalho); processamento tecnológico e térmico inadequado; ausência de monitoramento constante das BPF.

\section{Procedimentos metodológicos}

O estudo foi desenvolvido com base em visitas de inspeção visual e aplicação do check list (RDC $\mathrm{n}^{\circ}$ 275), no Estado do Rio Grande do Sul, em propriedades familiares que utilizam como matéria-prima o leite, transformando-o em inúmeros produtos de origem animal para alimentação humana. O check list da ANVISA foi utilizado devido à ausência de um semelhante para obtenção de dados por parte do Ministério da Agricultura. Realizou-se a pesquisa de abordagem quantitativa descritiva, a tabulação dos dados foi feita no programa estatístico SPSS (Statistical Package for the Social Sciences) 18.0 e Excel. Segundo Girelli et al., (2015) teorias e padrões respaldam-se em medições numéricas e análises estatísticas.

A pesquisa sobre a condição higiênico-sanitária de agroindústrias familiares que produzem leite e derivados, no Estado do Rio Grande do Sul, foi desenvolvida em 10 unidades produtoras, abrangendo um total de nove municípios, que são: Santa Maria, Silveira Martins, Júlio de Castilhos, Tupanciretã, ljuí, Santo Ângelo, Santana do Livramento, Boa Vista do Buricá e Cerro Largo. Duas agroindústrias localizam-se no mesmo município, Silveira Martins. O formulário e sua interpretação visual evidenciou a realidade das unidades familiares com relação à sua infraestrutura, equipamentos, higiene, manipuladores e documentos. 
Para a seleção das 10 agroindústrias participantes, buscou-se contato direto em quatro, já de conhecimento do autor, em uma foi obtido o contato através da Prefeitura Municipal de Santa Maria, e nas outras cinco foi utilizada uma tabela fornecida pela Secretaria de Desenvolvimento Rural, Pesca e Cooperativismo do Governo do Estado do Rio Grande do Sul (disponível em http://www.sdr.rs.gov.br), onde através dos nomes das unidades referidas buscou-se o contato eletrônico e telefônico.

As propriedades participantes foram escolhidas pela disponibilidade dos produtores em relação ao tempo e acessibilidade, localização e resposta do contato inicial via telefone, e também pelo prévio conhecimento do autor das respectivas localizações. O período de coleta de dados foi de agosto/2016 até fevereiro/2017.

No momento das visitas, foi utilizada a RDC $n^{\circ} 275$, de 21 de outubro de 2002, da Agência Nacional de Vigilância Sanitária de alcance federal e com atuação na área de alimentos, a qual aplica-se aos estabelecimentos processadores/industrializadores nos quais sejam realizadas algumas das seguintes atividades: produção/industrialização, fracionamento, armazenamento e transporte de alimentos industrializados. Nessa resolução está presente a lista de verificação relativa às Boas Práticas de Fabricação, que foi utilizada como modo de entrevista e inspeção visual das unidades.

Classificaram-se os grupos de acordo com a sequência da própria ckeck list: Grupo 1 (edificação e instalações); Grupo 2 (equipamentos, móveis e utensílios); Grupo 3 (manipuladores); Grupo 4 (produção e transporte de alimento); Grupo 5 (documentação). Cada grupo contém subgrupos e estes diversos itens de avaliação e subitens, a seguir na Tabela 1.

Tabela 1 - Grupos e itens/subitens avaliados

\begin{tabular}{cc}
\hline Grupos & Itens/subitens avaliados \\
\hline Grupo 1 & 78 \\
Grupo 2 & 21 \\
Grupo 3 & 14 \\
Grupo 4 & 33 \\
Grupo 5 & 17 \\
\hline
\end{tabular}

Fonte: Dados da pesquisa

Os proprietários e responsáveis pela produção estavam presentes durante toda visita à propriedade, mostrando as dependências, relatando melhorias, aperfeiçoamentos na propriedade agroindustrial, respondendo às perguntas acerca do processo produtivo. Cada item era marcado conforme as seguintes expressões: Sim (S); Não (N); ou Não se aplica (NA), cabendo ressaltar que das 10 propriedades analisadas, três responderam à pesquisa via e-mail e através de contato telefônico. O trabalho foi aprovado no Comitê de Ética, sob número 008/16.

\section{Apresentação e análise dos resultados}

A apresentação e análise dos resultados foi distribuída em subitens para melhor visualização, sendo eles: produtos comercializados; curso de boas 
práticas/manipulação de alimentos; avaliação dos grupos 1, 2, 3, 4 e 5; e avaliação geral das propriedades e grupos.

\subsection{Produtos comercializados}

Os produtos derivados do leite que são transformados nas agroindústrias são os seguintes: queijos (muçarela, colonial, colonial temperado, com iogurte, minas frescal, provolone); manteiga; ricota; iogurte; bebida láctea; leite integral pasteurizado; leite semidesnatado pasteurizado; nata; bebida láctea; doce de leite; requeijão; rapadura de leite. Segue no Quadro 1 o resumo dos tipos e quantidade dos produtos.

Quadro 1 - Produtos processados e respectivas quantidades nas agroindústrias que participaram do estudo

\begin{tabular}{|c|c|c|}
\hline Laticínio/Agroindústria & Produtos Processados & Quantidade \\
\hline A & $\begin{array}{c}\text { Queijo (muçarela, colonial e } \\
\text { temperado), manteiga, ricota e } \\
\text { iogurte }\end{array}$ & $\begin{array}{c}\text { Queijos: } 200 \mathrm{~kg} / \mathrm{semana} \\
\text { manteiga: } 18 \mathrm{~kg} / \mathrm{semana} \text {; ricota: } \\
20 \mathrm{~kg} / \mathrm{semana} \text {; iogurte: } 50 \\
\text { L/semana }\end{array}$ \\
\hline B & $\begin{array}{l}\text { Queijo colonial, iogurte, bebida } \\
\text { láctea, leite integral, leite } \\
\text { semidesnatado e nata }\end{array}$ & $\begin{array}{l}\text { Queijo: } 280 \text { kg/mês; iogurte: } \\
200 \text { L/mês; bebida láctea: } 360 \\
\text { L/mês; leite integral: } 3.600 \\
\text { L/mês; leite semidesnatado: } \\
400 \text { L/mês; nata: } 35 \text { kg/mês }\end{array}$ \\
\hline C & Queijo colonial & Queijo: 600 kg/mês \\
\hline D & $\begin{array}{l}\text { Queijo (colonial, com iogurte e } \\
\text { temperado, minas frescal) e } \\
\text { ricota }\end{array}$ & Queijo + ricota:500 kg/semana \\
\hline $\mathrm{E}$ & $\begin{array}{l}\text { Queijo (colonial, muçarela e } \\
\text { temperado), leite, nata, ricota, } \\
\text { iogurte, bebida láctea, doce de } \\
\text { leite, manteiga e requeijão }\end{array}$ & $\begin{array}{c}\text { Produção sob demanda, } \\
\text { alternando os dias da semana } \\
\text { para os produtos }\end{array}$ \\
\hline $\mathbf{F}$ & $\begin{array}{l}\text { Queijo (colonial, muçarela, } \\
\text { provolone, temperado e com } \\
\text { iogurte) e ricota }\end{array}$ & Queijo + ricota: 170 kg/semana \\
\hline G & $\begin{array}{c}\text { Queijo, bebida láctea, rapadura } \\
\text { de leite e doce de leite }\end{array}$ & $\begin{array}{l}\text { Sem mensuração porque estão } \\
\text { retornando à atividade (motivo } \\
\text { doença) }\end{array}$ \\
\hline $\mathbf{H}$ & Queijo colonial e iogurte & $\begin{array}{l}\text { Queijo: } 50 \mathrm{~kg} / \text { dia; iogurte: } \\
\text { produzido sob demanda }\end{array}$ \\
\hline I & Queijo colonial e doce de leite & $\begin{array}{l}\text { Queijo: } 878 \text { kg/mês; doce de } \\
\text { leite: } 295 \text { kg/mês }\end{array}$ \\
\hline J & logurte & 8.000-10.000 L/mês \\
\hline
\end{tabular}

Fonte: Dados da pesquisa

O queijo é o derivado mais produzido nas agroindústrias porque possui maior valor agregado na venda e também por características culturais de consumo das 
famílias. Esse derivado demanda uma quantidade de leite por quilograma que varia conforme a propriedade (características físico-químicas) na sua produção. É possível, visualizando-se O Gráfico 1, observar os percentuais das agroindústrias por tipo de produto.

\section{Gráfico 1 - Percentual de produtos das agroindústrias}

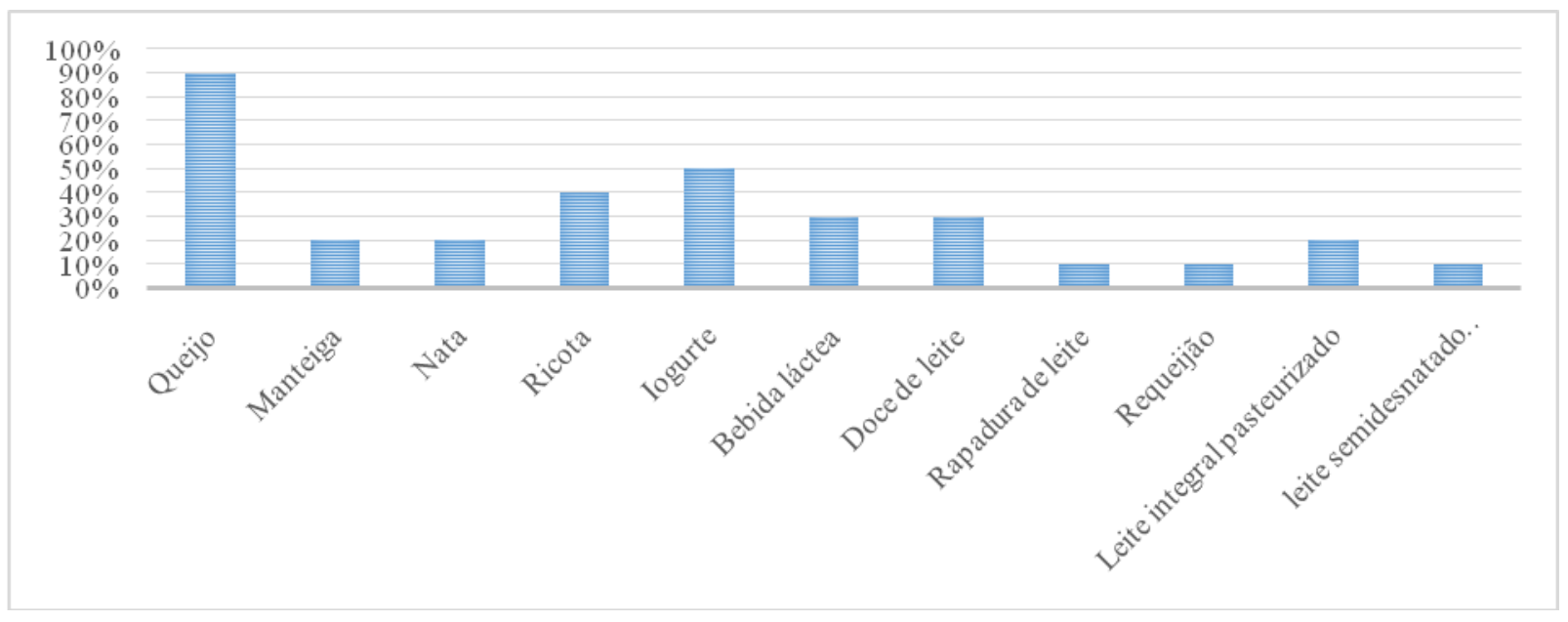

Fonte: Dados da pesquisa

Segundo Simioni, Hoff e Silva (2016), a diversificação do sustento rural se define pela busca da unidade familiar ou indivíduo, através de bens e tarefas, em melhorar sua qualidade de vida naquele meio, juntamente com a utilização de suas capacidades sociais. Esse padrão de segurança e variedade de produtos protege os produtores das incertezas do mercado específico de produtos e marcas.

Com a diversidade produtiva, os produtos elaborados precisam estar ausentes de contaminação em todas as etapas produtivas. Nesse sentido, item importante é um Curso de Boas Práticas de Fabricação realizado pelos responsáveis pela produção.

\subsection{Curso de Boas Práticas de Fabricação/Manipulação de alimentos}

Os laticínios encaixam-se na descrição do estabelecimento de alimentos produzidos/industrializados onde se efetua um conjunto de operações e processos, com a finalidade de obter um alimento elaborado, assim como o armazenamento ou o transporte de alimentos e/ou suas matérias-primas (BRASIL, 1997). O conceito mais completo, unindo as duas legislações (Portaria 326/Ministério da Saúde e Portaria 368/Ministério da Agricultura, Pecuária e Abastecimento), seria de que boas práticas de fabricação/elaboração são um conjunto de itens que se verificados integralmente garantem a qualidade, originando um alimento inócuo e saudável, em qualquer etapa de seu processamento, desde a matéria-prima e insumos até o produto final.

$\mathrm{Na}$ análise dos laticínios, oito apresentavam somente uma pessoa envolvida na produção/industrialização que possuía o curso de BPF, dois apresentavam duas pessoas com o curso, sendo que em uma destas eram dois tecnólogos em alimentos. Todos os produtores relatam o conhecimento da existência do curso por 
diversos meios, como internet, ações do governo local, universidades, órgãos sindicais, porém, no entendimento deles, somente uma pessoa com o curso é suficiente, sendo o requisito essencial para atender à legislação. Em estudo semelhante, Devides et. al., (2014) mostrou que os principais motivos para a realização do curso de capacitação foram ampliação dos conhecimentos (36,0\%) e exigência da vigilância sanitária (47,0\%).

\subsection{Avaliação do check list}

O check list da Resolução $n^{\circ} 275$ da ANVISA foi categorizado em quatro grupos, para melhor visualização dos resultados em percentuais, com possíveis respostas em sim, não e não se aplica. As avaliações de não se aplica de alguns itens no grupo documentação foram de acordo com a resposta anterior no mesmo subitem, ausentando-se um procedimento, então esse não era aplicado.

\section{Grupo 1}

O Grupo 1 engloba as edificações e instalações das agroindústrias: área externa; acessos; área interna; pisos; tetos; paredes e divisórias; portas; janelas e outras aberturas; escadas e estruturas auxiliares; instalações sanitárias e vestiários para os manipuladores; instalações sanitárias para visitantes e outros; lavatórios na área de produção; iluminação e instalação elétrica; ventilação e climatização; higienização das instalações; controle integrado de pragas; abastecimento de água; manejo de resíduos; esgotamento sanitário; leiaute. Em alguns dos itens citados, como exemplo, em instalações sanitárias e vestiários para os manipuladores, aparecem 15 subitens de avaliações. Podemos visualizar o Grupo 1 no Gráfico 2.

\section{Gráfico 2 - Edificações e instalações}

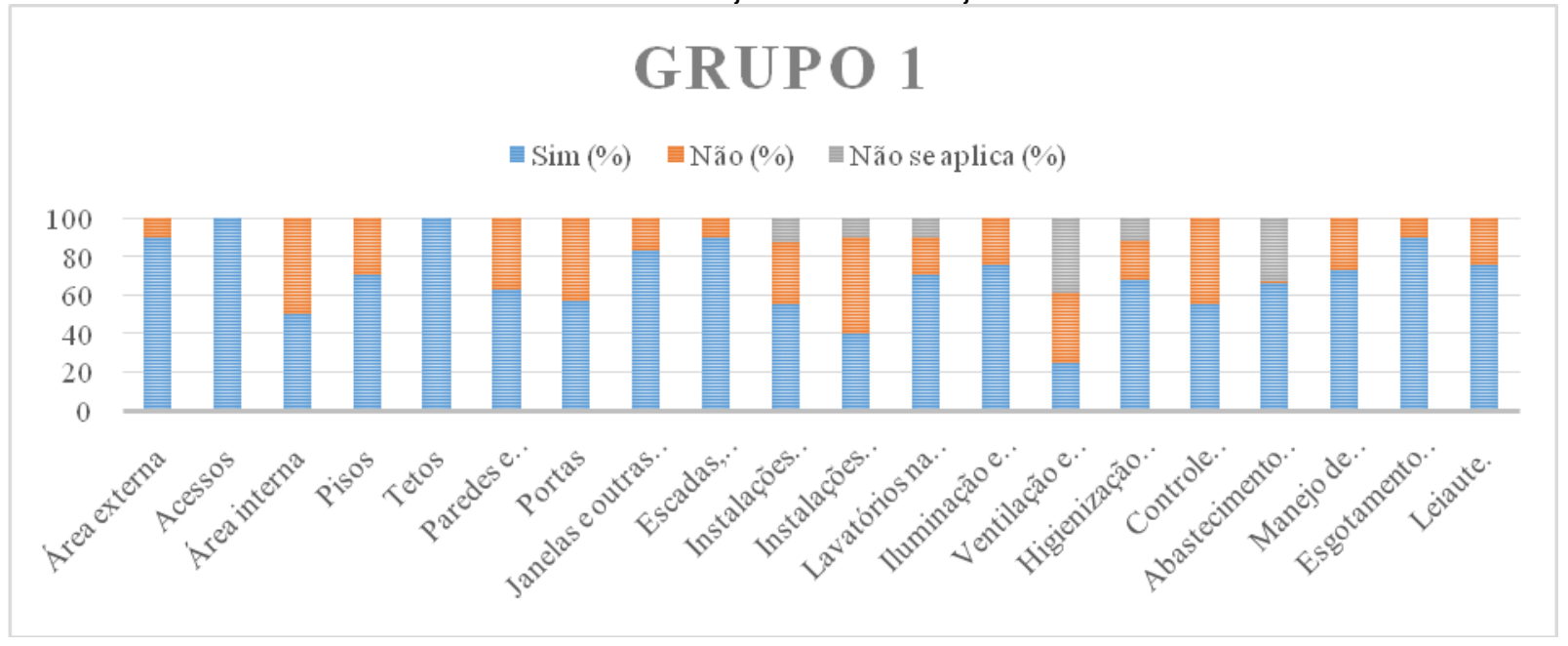

Fonte: Dados da pesquisa

O item que mais apresentou inadequações foi o entorno das agroindústrias, $20 \%$ retratavam focos de poeira, objetos em desuso, falta de cercamento das edificações e trânsito de animais domésticos, como cães e gatos. A manutenção do entorno em boas condições reflete a qualidade do produto final, pois a organização 
geral fora do estabelecimento interfere no fluxo e higiene no seu interior. Todas as instalações eram isoladas e não comuns às residências das famílias, evitando assim o fluxo de pessoas não autorizadas na circulação da área de produção, sem EPI (equipamentos de proteção individual) e não uniformizadas. A principal inadequação que determinou $50 \%$ de conformidade na área interna foi a presença de inúmeros objetos em desuso em muitas propriedades, por vezes sujos, atrapalhando o fluxo de produção.

Em 70\% das propriedades verificou-se sistema de drenagem insuficiente, de acordo com o tamanho das instalações, e ausência de ralos que impedissem a entrada de pragas. Na totalidade, os pisos apresentavam adequações, pois eram lisos, impermeáveis, íntegros, dessa maneira facilitando a limpeza. Em 80\% das agroindústrias as paredes dispõem de adequado estado de conservação, de cor clara, lisas, livres de frestas e rachaduras/trincas, porém, 90\% não apresentavam ângulo abaulado entre parede/piso e entre parede/teto, dificultando a higienização constante do local e evitando o acúmulo de água.

As portas, em $80 \%$ dos casos, têm superfície lisa, de fácil higienização, ajustadas aos batentes, sem falhas de revestimento. Em $90 \%$ dos casos apresentavam adequação estrutural (livres de falhas, rachaduras, umidade, descascamento e outros). Em relação ao fechamento automático e proteção contra insetos e vetores, as portas, em 100\% dos casos, não estavam conformes. Em contraste, as janelas apresentaram redução no nível de facilidade quanto à higienização e manutenção (60\%), porém, $100 \%$ apresentavam proteção contra pragas e insetos com telas. As escadas e degraus destinados ao acesso das agroindústrias conferiam $90 \%$ na avaliação, com estrutura em bom estado de conservação e fáceis de manter a limpeza diária.

Nas agroindústrias não havia instalações sanitárias separadas para cada gênero, eram ambientes comuns, com poucos empregados, mão de obra praticamente toda familiar. As instalações sanitárias para visitantes, em $50 \%$ dos casos, caracterizam-se como sendo as mesmas dos proprietários/funcionários. Em $70 \%$ inexistiam torneiras com acionamento automático e em 90\% não havia portas com fechamento automático. Em se tratando das lixeiras com acionamento não manual, 40\% das propriedades não possuíam, em relação aos procedimentos corretos e necessários para higienizar as mãos, em 90\% dos casos cartazes eram inexistentes. Com relação aos lavatórios na área de produção, 80\% apresentavam lavatórios em condições de higiene, posição e número adequado ao fluxo de produção,

A luz natural/artificial estava adequada à produção em 50\% das propriedades, em $60 \%$ das instalações internas, as luminárias continham proteção adequada, e em $90 \%$ as instalações elétricas apresentavam-se revestidas por tubulações isolantes. Observando-se o fluxo de produção, ventilação e circulação de ar capazes de garantir o conforto térmico e o ambiente livre de fungos, gases, fumaça, pó, partículas em suspensão e condensação de vapores sem causar danos à produção, $90 \%$ de adequação. Somente $30 \%$ apresentavam ventilação artificial (arcondicionado) e 10\% desses com higienização adequada, os outros dois que possuem ar-condicionado na área de produção não possuem registro periódico de higienização do equipamento. Com relação ao sistema de exaustão e/ou insuflamento com troca de ar capaz de prevenir contaminações, $80 \%$ das 
propriedades não possuem sistemas artificiais para evitar contaminações com filtros adequados, e 50\% apresentam captação e direção da corrente de ar que seguem a direção da área contaminada para a área limpa.

As agroindústrias, em $90 \%$ dos casos, apresentavam responsável devidamente capacitado para as operações de higienização nas instalações. Nenhuma agroindústria mostrou existência de registro da higienização, ponto importante abordado no curso de boas práticas, realizado por eles. Das unidades, $50 \%$ apresentavam os produtos guardados em locais apropriados, de modo a evitar a contaminação cruzada com os alimentos, preparados ou matérias-primas. De modo geral, a higienização era realizada frequentemente.

Nas propriedades, $80 \%$ das instalações não apresentavam vetores ou pragas e quando questionados, $30 \%$ dos produtores informaram que realizavam controle integrado de pragas sem contratar empresa especializada. Em um estudo realizado em 12 propriedades informais de Santa Catarina, em Seara, todas utilizavam os gatos em todas as unidades para controle de pragas (CARVALHO, LINDNER E FARIÑA, 2016). Esse fato vai de encontro aos preceitos de boas práticas e padrões de higiene operacional, pois poderá acarretar contaminação biológica e física dos alimentos de produtos de origem animal.

Dentre as unidades do estudo, 20\% apresentavam abastecimento de água pela rede pública e $80 \%$ proveniente de poços artesianos ou vertentes. Também, 90\% apresentavam instalações de abastecimento de água adequadas, instalações e encanamentos, além de empresa terceirizada responsável pela limpeza do reservatório de água e cloração, com monitoramento constante. Mencionando a diferença em propriedades informais no estudo de Carvalho et al.:

Todos os produtores demonstraram interesse na cloração, caso a água da propriedade apresentasse problema de contaminação. Se ela não apresentasse problemas de contaminação de origem microbiológica, os produtores preferiam não utilizar tratamento químico nessa água. A preocupação com a qualidade da água era evidente, pois a água utilizada no processo de fabricação do queijo era a mesma do consumo familiar (CARVALHO et al., v. 70, n. 5, p. 259).

A qualidade da água para consumo humano e seu padrão de potabilidade deve estar sujeita à legislação oficial. O sistema de abastecimento de água para consumo humano é definido na Portaria $n^{\circ}$ 2.914/2011, do Ministério da Saúde: instalação composta por um conjunto de obras civis, materiais e equipamentos, desde a zona de captação até as ligações prediais, destinada à produção e ao fornecimento coletivo de água potável, por meio de rede de distribuição. Ainda na mesma portaria, solução alternativa individual de abastecimento de água para consumo humano caracteriza-se por uma modalidade de abastecimento de água para consumo humano que atenda a domicílios residenciais com uma única família, incluindo seus agregados familiares. No estudo de Pereira et al. (2014), das 32 queijarias artesanais nos municípios de São João Del-Rei, Tiradentes e Lagoa Dourada, aproximadamente um terço dos produtores avaliados não realizava qualquer tipo de tratamento na água destinada à queijaria, número inferior ao aqui apresentado.

Não existia acúmulo de lixo durante as visitas, em $80 \%$ das agroindústrias os recipientes para coleta de resíduos estavam devidamente identificados, 
higienizados, de fácil transporte, e acionamento não manual. Uma área destinada especificamente para o armazenamento dos resíduos estava presente em apenas $40 \%$ das propriedades analisadas, uma área adequada para depósito evita mau cheiro, presença de vetores e pragas e contaminação microbiológica nos produtos finais.

Na maioria das agroindústrias, mais precisamente em $90 \%$, o esgoto sanitário era destinado a fossas ou ligados à rede pública, sendo somente uma das propriedades com destinação diferente, um sumidouro. Não existe tratamento para os efluentes, somente o soro é destinado à alimentação animal em algumas propriedades. De acordo com Andrade (2016), são utilizados entre 2 e 5 litros de água para higienização em uma indústria que utiliza leite como matéria-prima, consequentemente eliminando uma grande quantidade de resíduos biodegradáveis, e também que todos resíduos de produção podem ser tratados juntos, somente o soro residual que não, por apresentar elevada e complexa concentração orgânica, causando prejuízo ao meio ambiente.

Todas as agroindústrias apresentavam número, capacidade e distribuição das dependências de acordo com o ramo de atividade, volume de produção e expedição. Contudo, $50 \%$ das agroindústrias apresentavam dependências para recepção, depósito de matéria-prima, ingredientes e embalagens em uso comum às áreas de produção, armazenamento e expedição de produto final, atrapalhando dessa forma, o processo produtivo e propiciando a contaminação dos produtos prontos inócuos com aqueles externos à manipulação sem um fluxo de material definido.

\section{Grupo 2}

O Grupo 2 abrange equipamentos, móveis e utensílios que compõem a agroindústria, como pode ser observado no Gráfico 3.

Gráfico 3 - Equipamentos, móveis, utensílios e sua higienização

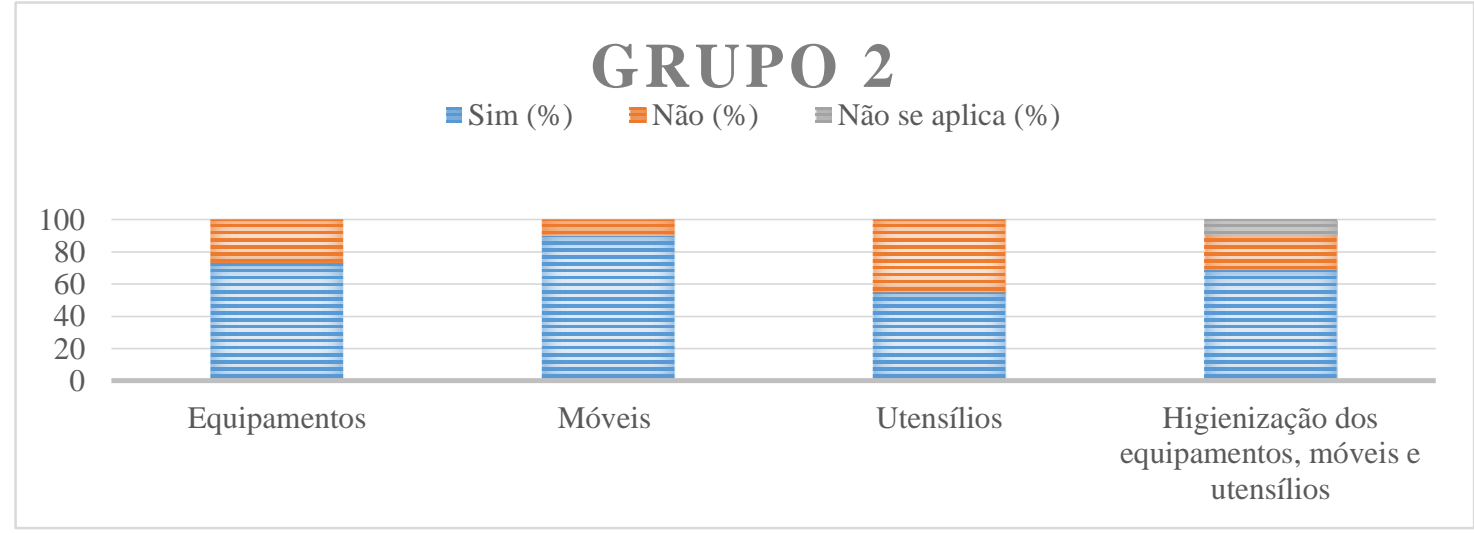

Fonte: Dados da pesquisa

Os equipamentos, móveis e utensílios adequados às atividades a que se destinavam, da linha de produção, com desenho e número adequado ao ramo, em 90\% estavam dispostos de forma a permitir fácil acesso e higienização adequada, com superfícies em contato com alimentos lisas, íntegras, impermeáveis, resistentes à corrosão, de fácil higienização e de material não contaminante. 
Apenas 30\% apresentavam registros que comprovem: controle de temperatura de câmaras frias, pasteurização, manutenção preventiva de maquinários/equipamentos e calibração de instrumentos de aferição. Todas as agroindústrias apresentaram mobiliário adequado ao ramo de atividade por eles desenvolvida (resistentes, impermeáveis), contudo, duas propriedades apresentavam móveis de madeira utilizados em algumas etapas da produção/manipulação do produto final.

Com relação aos utensílios utilizados no processo de fabricação dos derivados, $80 \%$ não possuíam local adequado para armazenamento, ficando expostos a focos de contaminações ambientais e de suas matérias-primas. Estavam em número adequado às funções, $90 \%$ das agroindústrias.

Todos os estabelecimentos apresentavam profissional capacitado com o curso e efetiva higienização dos equipamentos/maquinários, móveis e utensílios, entretanto, nenhum efetuava o devido registro das operações de higienização, para um melhor controle. Um total de $50 \%$ dos produtos de limpeza eram comprados em supermercados e o restante, 50\%, em lojas especializadas. Em 70\% das propriedades os produtos de higienização não estavam identificados e guardados em local adequado, sendo espalhados pelas dependências dos estabelecimentos. Já em $80 \%$ havia utensílios específicos de produção disponíveis e adequados para o desempenho daquela atividade e em bom estado de conservação. A higienização desses itens era adequada em $90 \%$ das agroindústrias.

Na higienização dos utensílios obteve-se um número de $9 \%$ não se aplica, em razão de não avaliação de alguns subitens do título em 3 agroindústrias. Elevado atendimento de móveis foi percebido, pois as agroindústrias, em sua totalidade, apresentavam aqueles necessários ao processo.

\section{Grupo 3}

O Grupo 3 compreende manipuladores: vestuário; hábitos higiênicos; estado de saúde; programa de controle de saúde; equipamento de proteção individual; programa de capacitação dos manipuladores e supervisão. O grupo 3 é representado pelo Gráfico 4. 
Gráfico 4 - Manipuladores e hábitos higiênicos

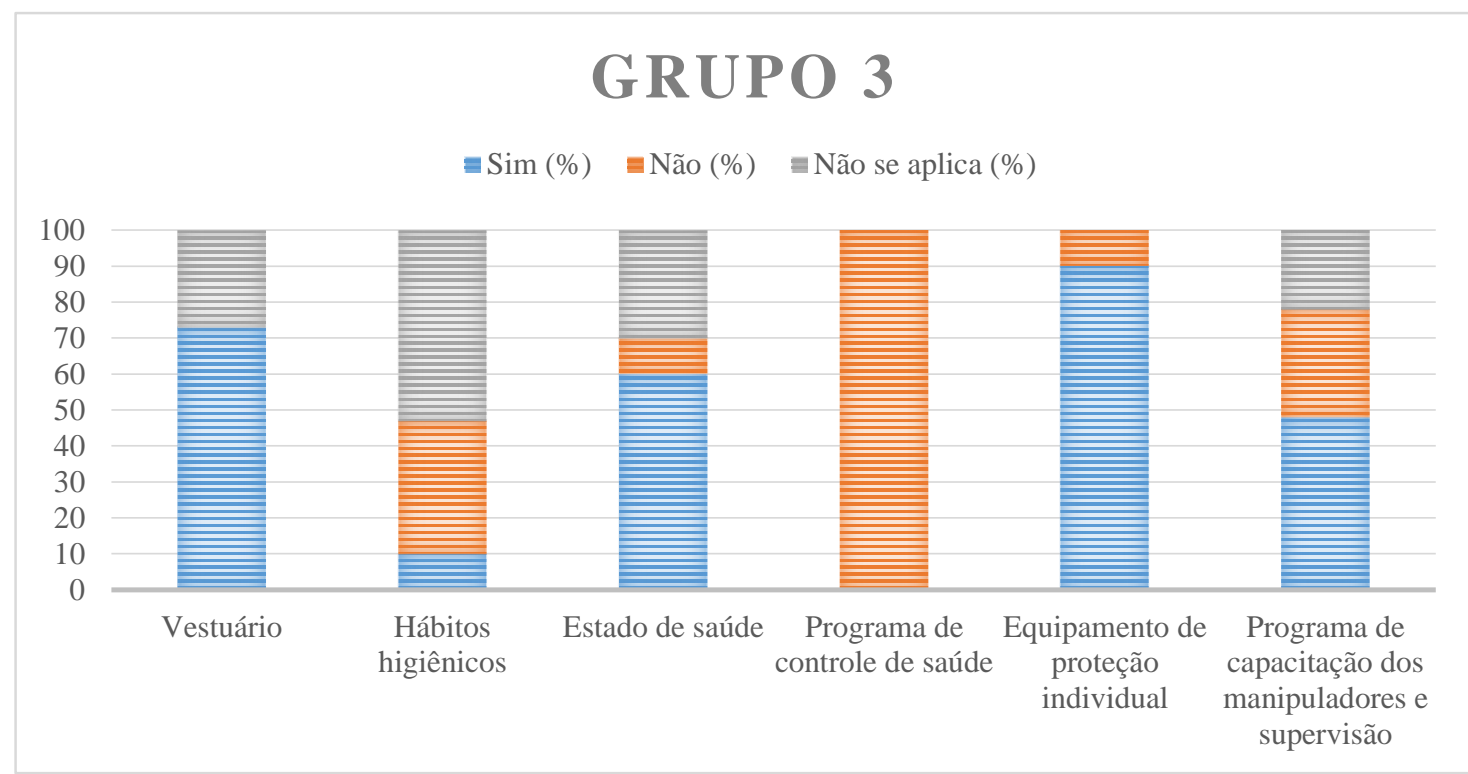

Fonte: Dados da pesquisa

Totalizando $80 \%$, a utilização de uniforme de trabalho na cor clara estava adequada à atividade e exclusiva para área de produção, e em $90 \%$ limpos e em adequado estado de conservação.

Os hábitos higiênicos: lavagem cuidadosa das mãos antes da manipulação de alimentos, após interrupções e depois do uso de sanitários; manipuladores não espirram sobre os alimentos, não cospem, não tossem, não fumam, não manipulam dinheiro ou não praticam outros atos que possam contaminar o alimento, só foi possível avaliar em duas unidades, porque em $80 \%$ da pesquisa o horário das visitas aconteceu fora do horário de produção ou a pesquisa foi enviada por e-mail. Dado interessante, $90 \%$ das propriedades não apresentavam cartazes de orientação aos manipuladores sobre a correta lavagem das mãos e demais hábitos de higiene, afixados em locais apropriados e visíveis.

O estado de saúde dos manipuladores leva em consideração: ausência de afecções cutâneas, feridas e supurações; ausência de sintomas e infecções respiratórias, gastrointestinais e oculares. Pela inspeção visual e perguntas, $60 \%$ não apresentavam e $30 \%$ não foi possível avaliar. Nenhum proprietário das agroindústrias realizava acompanhamento e controle da saúde, também inexistia supervisão periódica do estado de saúde dos manipuladores, além de falta de registro dos exames periodicamente realizados por eles. Grande parte das agroindústrias possui equipamento de proteção individual (EPI), totalizando 90\%.

A importância de um programa de capacitação contínuo, direcionado ao melhoramento na manipulação dos alimentos é inestimável, porém, apenas 10\% das unidades se reciclam. A existência de supervisão na higiene pessoal e manipulação dos alimentos sobe para $80 \%$, devido à predominância familiar na manipulação, e os produtores se auto avaliam. Um questionário aplicado para avaliar o incremento de conhecimento de um Curso de Boas Práticas de Fabricação, no início do curso (avaliação diagnóstica) e último dia curso (avaliação final), constatou que questões referentes ao item DTAs (doenças transmitidas por alimentos) foram as que tiveram a maior porcentagem de acertos na avaliação diagnóstica (82\%) e final (94\%) e, 
também, a questão relacionada ao controle de temperatura apresentou menor porcentagem de acertos inicial (41\%) e, no entanto, esse percentual praticamente dobrou na avaliação final, passando para $81 \%$ de respostas corretas (DEVIDES, 2014).

\section{Grupo 4}

O Grupo 4 é avaliado pela produção e transporte do produto final: matériaprima, ingredientes e embalagens; fluxo de produção; rotulagem e armazenamento do produto final; controle de qualidade do produto final; transporte do produto final. Para demonstrar o Grupo 4, segue o Gráfico 5.

\section{Gráfico 5 - Produção e transporte do alimento}

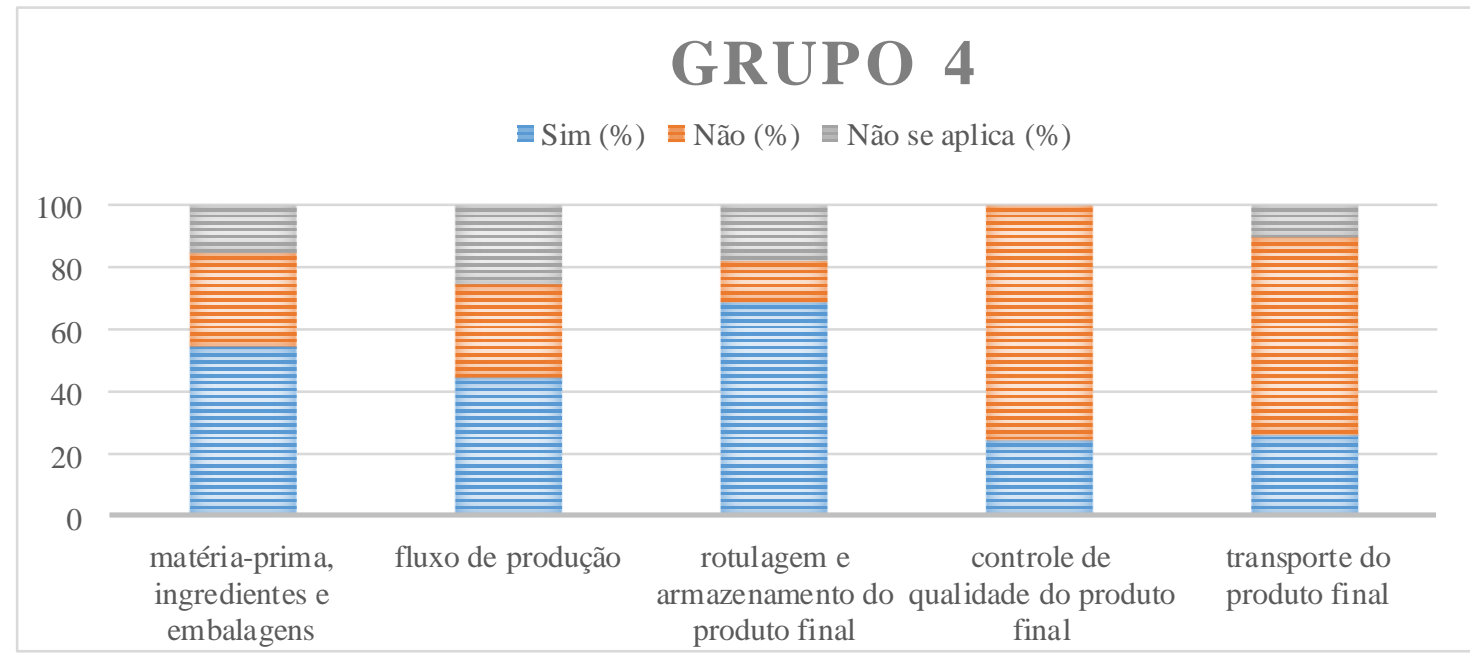

Fonte: Dados da pesquisa

Quanto aos itens como matérias-primas, ingredientes e embalagens, 90\% não são inspecionados na recepção, somente $10 \%$ das propriedades possuem planilhas de controle na recepção que indicam particularidades quanto a caraterísticas sensoriais, temperatura, entre outros. Na totalidade das propriedades não há controle na entrada sobre as matérias-primas e ingredientes, se estão aprovados, identificados, o mesmo ocorrendo com as embalagens, que não ficam em local devidamente destinado quando reprovadas. Essas falhas só são percebidas na hora de sua utilização. Quanto à legislação aplicada nos rótulos, com identificação dos ingredientes e matérias que compõem os produtos, 100\% estão de acordo.

Metade das propriedades, 50\%, seguem padrão de segurança quanto a critérios de segurança alimentar na seleção de matéria-prima. No que diz respeito ao armazenamento, $70 \%$ dos casos analisados possuem local apropriado e devidamente arrumado, longe do solo, afastado das paredes de forma a facilitar a circulação do ar e a higiene do local.

Todas as propriedades, 100\%, atendem à ordem de entrada quanto aos ingredientes, prazos de validade, em virtude do volume da produção. Assim como o armazenamento dos ingredientes, 60\% das agroindústrias mantêm as embalagens que serão utilizadas em local adequado, distinto, distante da manipulação. Em 100\% dos casos estudados, os equipamentos estavam adequados, em relação à rede de 
frio, existiam câmaras frias compatíveis ao número de produtos fabricados e o fluxo de saída.

Em todas as propriedades, os locais de pré-preparo eram isolados da área de preparo. Em $60 \%$ delas havia controle da circulação e acesso do pessoal realizado pelos próprios manipuladores e proprietários. No que tange à conservação adequada de materiais destinados ao reprocessamento, não se aplica porque os produtos sofrem somente um ciclo de fabricação e são destinados ao consumo. Em $80 \%$, o ciclo produtivo não é ordenado, linear e sem cruzamento.

Em todas as propriedades agroindustriais, os dizeres de rotulagem estavam de acordo com a legislação vigente, de competência do serviço de inspeção municipal ou estadual. Quanto às embalagens, $90 \%$ dos produtos finais estavam acondicionados em embalagens adequadas e íntegras. Os alimentos armazenados eram separados por tipo ou grupo, sobre estrados distantes do piso ou sobre paletes, bem conservados e limpos ou sobre outro sistema aprovado, afastados das paredes e distantes do teto, de forma a permitir apropriada higienização, iluminação e circulação de ar. Havia ausência de material estranho, estragado ou tóxico, em todas as propriedades. Quanto ao controle adequado e existência de planilha de registro de temperatura, para ambientes com controle térmico, ausência em $90 \%$ das propriedades. Todas as agroindústrias deste estudo estavam com a rede de frio adequada ao volume e aos diferentes tipos de alimentos.

Numa totalidade de $70 \%$ não se aplica, não retornando produtos vencidos, avariados, devolvidos ou recolhidos do mercado, devidamente identificados e armazenados em local separado e de forma organizada. Não se aplica $90 \%$, no quesito produtos finais aguardando resultado analítico ou em quarentena e aqueles aprovados, devidamente identificados, porque as propriedades não realizam controle do produto final abordado posteriormente, são enviados diretamente para o comércio.

Em 70\% das agroindústrias inexiste controle de qualidade do produto final. Já em outras $70 \%$ não existe programa de amostragem para análise laboratorial do produto final, o mesmo ocorrendo também em $70 \%$ com a não existência de laudo laboratorial atestando o controle de qualidade do produto final, assinado pelo técnico da empresa, responsável pela análise ou expedido por empresa terceirizada. Já em 90\% das propriedades agroindustriais, inexistem equipamentos e materiais necessários para análise do produto final realizada no estabelecimento. O controle final para pequenas propriedades é discutido por Batalha, Buainain e Souza Filho:

\footnotetext{
Este é um desafio importante para os agricultores familiares, uma vez que a estabilização de padrões de qualidade exigidos pelos mercados relevantes pressupõe a adoção de tecnologias e procedimentos que em muitos casos não são compatíveis, pelo menos no curto prazo, com as condições gerais dos agricultores familiares. Essas condições podem referir-se tanto à capacidade financeira para adotar e manter processos produtivos mais custosos como à exigência de experiência e capacidade de gestão da propriedade que a maioria dos produtores não têm. Pode também se referir à escala insuficiente para justificar a incorporação de equipamentos necessários para assegurar a qualidade e estabilidade do padrão do produto (BATALHA, BUAINAIN E SOUZA FILHO, 2005)
} 
Em $80 \%$ dos casos, os produtos transportados não estão acondicionados na temperatura específica do rótulo, 90\% dos veículos encontram-se limpos, com cobertura para proteção de carga, o mesmo ocorre quanto a ausência de vetores e pragas urbanas ou qualquer evidência de sua presença como fezes, ninhos e outros. Quanto à integridade do produto no transporte, 80\% não mantém uma temperatura adequada, já no tocante ao transporte de outras cargas, 80\% não carregam outros alimentos conjuntamente.

Desse modo, ressalta-se que as particularidades acerca do processo de transporte dos alimentos oriundos da pequena agroindústria necessitam de ciclos rápidos e curtos até a destinação do consumidor, preservando assim as características quanto a perecibilidade (BATALHA, BUAINAIN E SOUZA FILHO, 2005).

\section{Grupo 5}

O Grupo 5 inclui a documentação: manual de boas práticas de fabricação; procedimentos operacionais padronizados; controle de potabilidade de água; higiene e saúde dos manipuladores; manejo dos resíduos; manutenção preventiva e calibração dos equipamentos; controle integrado de vetores e pragas; seleção das matérias-primas, ingredientes e embalagens; programa de recolhimento de alimentos. A seguir, o Gráfico 6 representa o Grupo 5.

\section{Gráfico 6 - Documentação das agroindústrias}

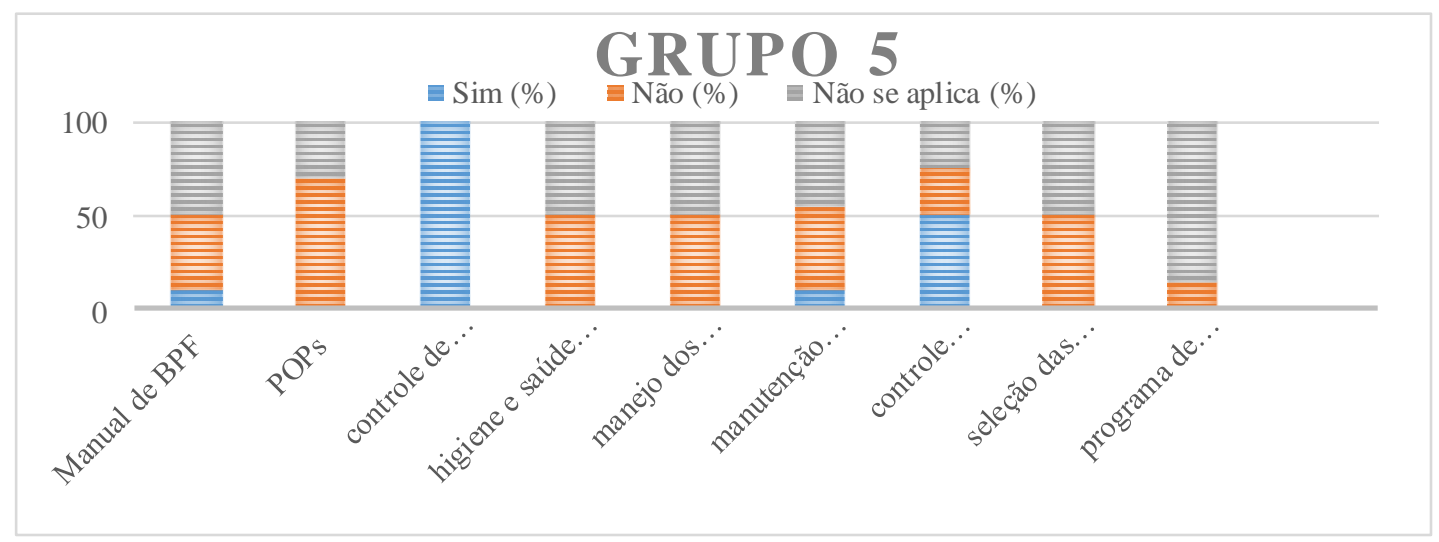

Fonte: Dados da pesquisa

Das propriedades analisadas na pesquisa, $100 \%$ possuíam o curso de BPF, mas somente uma apresentava o manual de BPF, instrumento escrito que elenca todo processo produtivo e seus pontos de controle. Os únicos POPs, integrantes do BPF, estavam sob responsabilidade e execução de empresas terceirizadas que atuavam no controle da potabilidade da água em 100\%, e controle integrado de vetor e pragas com $50 \%$.

Em 100\% das agroindústrias eram ausentes os seguintes POPs: higiene e saúde dos manipuladores; manejo dos resíduos; somente uma empresa realiza periodicamente manutenção e calibração dos equipamentos por empresa terceirizada. $\mathrm{Na}$ análise quanto à seleção de matérias-primas, ingredientes e embalagens, estas não tem nenhum tipo de registro da pré-seleção ou procedimento que caracterize sua identidade e qualidade. Quanto ao programa de recolhimento de alimentos, somente uma agroindústria apresentava, já que sua 
escala de produção, por vezes, resultava em devoluções devido à data de vencimento, caso que as demais não sofriam, por produzirem em menor escala, de acordo com as demandas dos mercados, feiras e outros estabelecimentos para os quais destinavam sua produção.

Em recente pesquisa com derivados de produtos suínos foi demonstrado que de sete agroindústrias do município Francisco Beltrão-PR, 4 não apresentavam BPF e 6 não apresentavam procedimentos padrão de higiene operacional (PPHO), relatando o desconhecimento e falta de exigência da fiscalização (THOMÉ, 2017). Percebe-se que esses argumentos contrariam a gestão com qualidade, que preza pela qualidade e garantia de seus produtos.

Os procedimentos operacionais padronizados (POPs) são roteiros descritivos para execução de atividades em todas suas etapas, servindo de complemento ao Manual de Boas Práticas de Fabricação. Nesse documento, é possível acompanhar as operações rotineiras desde a produção, armazenamento e transporte, objetivando assim a garantia da qualidade dos produtos e serviços, sem perder seu parâmetro. Cada etapa deve relatar as operações que totalizam os POPs, como: o responsável pela execução, momento, dia, material utilizado, equipamentos necessários, além dos equipamentos de proteção individual. Os POPs devem estar disponíveis para a supervisão conferir e aprovar as atividades realizadas, por profissionais capacitados, e também deverão ser acessíveis para inspeção de órgãos oficiais. (FREITAS, 2013).

\subsubsection{Avaliação geral das propriedades e grupos}

No final da Resolução $n^{\circ} 275 / 02$, está presente um critério de classificação do estabelecimento, conforme seus itens atendidos, dessa maneira: Grupo 1, de 76\%100\%; Grupo 2, 51-75\%; Grupo 3, 0-50\%. Nenhuma propriedade classificou-se no Grupo 1, 7 agroindústrias colocaram-se no Grupo 2 e três no Grupo 3. Pode-se observar na Tabela 2 a individualização dos itens atendidos.

Tabela 2 - Quantidade de itens e porcentagem de itens avaliados "sim" por agroindústria

\begin{tabular}{ccc}
\hline Agroindústria & Itens atendidos Sim & \% Itens atendidos Sim \\
\hline A & 86 & 52,76 \\
B & 87 & 53,76 \\
C & 93 & 57,05 \\
D & 92 & 56,44 \\
E & 104 & 63,80 \\
F & 70 & 42,94 \\
G & 85 & 52,14 \\
H & 92 & 56,44 \\
I & 76 & 46,62 \\
J & 111 & 68,09 \\
\hline
\end{tabular}

Fonte: Dados da pesquisa

A Tabela 3 contém a avaliação específica por grupos, já que cada um indica quantidade variável de itens em análise, colocando-se seus elementos como 100\%. O Grupo 5 apresentou quantidade expressiva de respostas "na", quando 
questionados sobre o cumprimento dos POPs, assim, foi constatada a inexistência em grande parte das propriedades, fato definitivo para essa classificação.

\begin{tabular}{cccccc}
\multicolumn{5}{c}{ Tabela 3 - Respostas "Sim", “Não" e "Não se aplica”, por grupo da RDC n² 275} \\
\hline Resposta & Grupo 1 & Grupo 2 & Grupo 3 & Grupo 4 & Grupo 5 \\
\hline Sim\% & $54,67 \%$ & $70,00 \%$ & $42,14 \%$ & $49,70 \%$ & $19,41 \%$ \\
Não \% & $23,33 \%$ & $26,19 \%$ & $32,14 \%$ & $36,06 \%$ & $38,82 \%$ \\
NA\% & $13,33 \%$ & $3,81 \%$ & $25,71 \%$ & $14,24 \%$ & $41,76 \%$ \\
\hline
\end{tabular}

Fonte: Dados da pesquisa

A Tabela 4 demonstra a média (\%) geral por grupos, aplicando-se o mesmo valor de importância para cada grupo ao realizar a média, ou seja, $20 \%$ de importância para cada grupo, visualizando-se assim que a resposta "sim" atingiu $47,18 \%$ das respostas nos grupos. Ainda com relação à Tabela, temos a média (\%) geral pelo total dos itens observados, elevando um pouco a média, já que soma todos os itens atendidos, não delimitando a importância dos grupos, pois há diferença no número de itens avaliados por grupos.

Tabela 4 - Médias gerais das avaliações pelos grupos e pelo total de itens avaliados

\begin{tabular}{ccc}
\hline Resposta & Média \% geral pelos grupos & Média \% geral pelo total de itens \\
\hline Sim \% & $47,18 \%$ & $55,03 \%$ \\
Não $\%$ & $31,31 \%$ & $28,65 \%$ \\
NA \% & $19,77 \%$ & $16,32 \%$
\end{tabular}

Fonte: Dados da pesquisa

Avaliando-se as edificações e instalações, pode-se dizer que, com 54,61\% de respostas "sim", as agroindústrias apresentam uma boa infraestrutura, deixando a desejar em itens como organização interna, que afetam diretamente a contaminação física, biológica e química, com 50\% e instalações sanitárias para visitantes também com $50 \%$, sendo que uma propriedade não apresenta instalações nem para os manipuladores.

Os dados mostram que o estudo está em consonância com os dados obtidos por Santos e Hoffman (2010), em que as melhores avaliações foram relativas aos grupos de higienização de equipamentos, móveis e utensílios, resultado de um curso de BPF assimilado, considerando-se um resultado de $70 \%$ como uma boa média final.

Tratando-se do Grupo 2, 90\% das superfícies de inox e material de rápida e fácil higienização demonstram a adequação dos equipamentos, móveis e utensílios para a produção. Com relação ao Grupo 3, referente aos manipuladores, com média final de $42,14 \%$, o dado de maior relevância do estudo foi que nenhuma unidade agroindustrial possui programa de saúde dos funcionários de maneira preventiva, favorecendo a transmissão de microrganismos causadores de doenças através da manipulação de alimentos.

Observando-se o Grupo 4, avaliação da matéria-prima, ingredientes e embalagens, nenhuma realiza controle prévio para averiguar não conformidades, somente na utilização e $70 \%$ não realizam controle de qualidade do produto final. $\mathrm{A}$ 
avaliação tanto higiênica como microbiológica do produto final proporciona ao consumidor a garantia e confiança no produto adquirido e, para a empresa, a certificação adequada dos seus processos de fabricação.

Com relação ao Grupo 5, em que Santos e Hoffman (2010) relatam 7,69\% de conformidade somente para os POPs e ausência de manual BPF, no presente estudo, englobando os dois, somente $19,41 \%$ de avaliações positivas. A falta de controle dos procedimentos e manuais presentes nos estabelecimentos para consultas, quando necessário e registro das informações, favorecem a contaminação dos ambientes de trabalho, processo de fabricação e produto final.

\section{Considerações finais}

Diante do exposto, durante a avaliação das 10 agroindústrias familiares, os grupos do check list com maiores porcentagens de respostas "sim", e consequentemente mais satisfatórios, foram as edificações e instalações, com $54,67 \%$ e equipamentos, móveis e utensílios com 70\%. A pior avaliação, partindo-se do pressuposto de igualdade de valoração entre os grupos, teve o grupo documentação, já que as agroindústrias possuem apenas $19,41 \%$ dos registros de suas operações rotineiras. A partir desses dados, observa-se uma estrutura satisfatória das agroindústrias pesquisadas, porém, as famílias ainda podem ganhar em qualidade e produtividade através de uma melhora contínua nos seus registros e controle de qualidade, como: capacitação constante; programa registro de exames de saúde; elaboração de manuais de boas práticas de fabricação com respectivo cumprimento; POPs de todas suas atividades relativas à produção; manutenção e calibração (através de empresa especializada) frequente dos equipamentos da agroindústria com seus registros; padronização de um controle integrado de vetores e pragas; programa de monitoramento da qualidade e seleção das matériasprimas, embalagens, produto final e rastreabilidade.

Para a pesquisa, na procura das propriedades que estavam dispostas a colaborar, o limitante foi de que muitas agroindústrias inquiridas não se dispuseram a participar devido à desconfiança de cobranças por parte da fiscalização, mesmo sem relação do estudo com os órgãos municipais e estaduais, apesar de todas apresentarem formalização com relação a estes órgãos. Segundo os proprietários, na sua totalidade, a grande dificuldade de instalação de uma agroindústria familiar é a alta cobrança estrutural para o reduzido volume industrial, se comparadas a indústrias de porte elevado. Outro ponto importante foi a procura de materiais para referências, com poucos trabalhos que analisaram a planta de unidades agroindustriais de derivados lácteos e seus respectivos controles de qualidade higiênico-sanitária.

Para pesquisas futuras, sugere-se buscar dados que explorem o quanto a fiscalização no seu respectivo âmbito de atuação pode ser eficiente para melhorar a qualidade dos derivados lácteos, de maneira a conhecer e evitar a propagação de microrganismos patogênicos, para que agroindústrias possam se inserir no mercado com a segurança da legislação e menos burocracia. As propriedades familiares pesquisadas relatam que desistiriam se não existisse a vocação de fabricar produtos próprios, pois o apoio e o retorno comercial são baixos. 


\section{REFERÊNCIAS}

ALBARELLO, E. P.; DEPONTI, C. M. Desenvolvimento regional e perfil das agroindústrias familiares na região do médio alto Uruguai. VII Seminário Internacional sobre Anais... Desenvolvimento Regional, Santa Cruz do Sul, RS, 2015.

ANDRADE, S. O. et al. Potencial poluidor de agroindústria de produção de queijo sobre o rio Piancó, Pombal, Paraíba. Revista Verde de Agroecologia e Desenvolvimento Sustentável, v. 11, n. 5, p. 168-176, 2016.

BATALHA, M. O.; BUAINAIN, A. M.; SOUZA FILHO, H. M. Tecnologia de gestão e agricultura familiar. Gestão Integrada da Agricultura Familiar, São Carlos, EdUFSCar 2005 .

BRASIL. Ministério da Saúde. Lei ${ }^{\circ} 8.080$, de 19 de setembro de 1990. Dispõe sobre as condições para a promoção, proteção e recuperação da saúde, a organização e o funcionamento dos serviços correspondentes e dá outras providências. Diário Oficial da República Federativa do Brasil, 20 de set. 1990.

BRASIL. Ministério da Saúde. Portaria n³26, de 30 de julho de 1997. Aprova o Regulamento Técnico sobre Condições Higiênico-Sanitárias e de Boas Práticas de Fabricação para Estabelecimentos Produtores/Industrializadores de Alimentos. Diário Oficial da República Federativa do Brasil, 01 de ago. 1997.

BRASIL. Ministério da Agricultura, Pecuária e Abastecimento. Portaria n 368, de 04 setembro de 1997. Regulamento Técnico Sobre as Condições Higiênico-Sanitárias e de Boas Práticas de Elaboração Para Estabelecimentos Elaboradores/Industrializadores de Alimentos. Diário Oficial da República Federativa do Brasil, 08 de ago. 1997.

BRASIL. Ministério da Saúde. Resolução RDC n² 275, de 21 de outubro de 2002. Dispõe sobre o Regulamento Técnico de Procedimentos Operacionais Padronizados aplicados aos Estabelecimentos Produtores/Industrializadores de Alimentos e a Lista de Verificação das Boas Práticas de Fabricação em Estabelecimentos Produtores/Industrializadores de Alimentos. Diário Oficial da República Federativa do Brasil, n. 206, seção 1, p. 126, 23 de out. 2002.

BRASIL. Ministério da Saúde. Portaria ${ }^{\circ}$ 2.914/2011. Dispõe sobre os procedimentos de controle e de vigilância da qualidade da água para consumo humano e seu padrão de potabilidade. Diário Oficial da República Federativa do Brasil, n. 239, seção 1, p.39-43, dez. 2011.

CARVALHO, M. M.; LINDNER, J.; FARIÑA, L. O. A produção de queijo colonial artesanal no município de seara, estado de Santa Catarina, frente à legislação brasileira. Revista do Instituto de Laticínio Cândido Tostes, Juiz de Fora, v. 70, n. 5, p. 253-261, set/out 2015. 
DEVIDES, G. G. G.; MAFFEI, D. F.; CATANOZI, M. P. L. M. Perfil socioeconômico e profissional de manipuladores de alimentos e o impacto positivo de um curso de capacitação em Boas Práticas de Fabricação. Brazilian Journal of Food Technology, Campinas, v. 17, n. 2, p. 166-176, abr/jun. 2014.

FREITAS, J. F.; LIMA, M. M.; SILVA, M. O.; RIBEIRO, M. L.; DIAS, R. Q.; PAOLI, T. M. P.; BERSANI, T. Agroindústria Familiar - Orientações para a formalização fiscal, ambiental e sanitária. Plano de Desenvolvimento da Agroindústria Familiar e do Empreendedorismo Rural (Agrolegal) GOVERNO DO ESTADO DO ESPÍRITO SANTO. Disponível em:

<http://agrotures.web2156.uni5.net/Arquivos/Manual\%20\%20Formaliza\%C3\%A7\%C3\%A 30\%20Agroind\%C3\%BAstria\%20-\%20Agrolegal.pdf>. Acesso em: 04 set. 2017.

GIRELLI, A, et al. Análise da aplicação das boas práticas de fabricação nas agroindústrias familiares do arranjo produtivo local do Vale do Taquari. Revista Eletrônica Científica da UERGS, v.1, n.1, p.50-57, dez/2015.

LANES, R. O. S. Entraves e avanços na implantação das boas práticas de fabricação em pequenas agroindústrias familiares em Júlio de Castilhos/RS. XXIII Seminário de Iniciação. Anais... ljuí, Rio Grande do Sul, 2015.

NICHELE, F.S.; WAQUIL, P. D. Agroindústria familiar rural, qualidade da produção artesanal e o enfoque da teoria das convenções. Ciência Rural, Santa Maria, v. 41, n. 12, p. 2230-2235, dez/2011.

PEREIRA, D. A. et al. Caracterização dos sistemas de abastecimento de água de queijarias da microrregião campo das vertentes. Revista do Instituto de Laticínios Cândido Juiz de Fora, v. 69, n. 4, p. 258-267, jul-ago/2014.

PREZOTTO, L. L. Uma concepção de agroindústria rural de pequeno porte. Revista de ciências humanas, Florianópolis: EDUFSC, n. 31, p. 133-153, abr/2002.

RIO GRANDE DO SUL. Decreto $n^{\circ} 49.341$, de 5 de julho de 2012. Cria o Programa de Agroindústria Familiar do Estado do Rio Grande do Sul, institui o selo de marca de certificação "Sabor Gaúcho" e dá outras providências. Disponível em:

<http://www.emater.tche.br/site/arquivos/agroindustria/Dec\%2049.341.pdf>. Acesso em: 30 ago. 2017.

ROCHA JUNIOR, C. J. G; CABRAL, R. M. O processo de transição de empreendimentos rurais tradicionais para as agroindústrias associativas no estado de Pernambuco: desafios para construir competências empreendedoras. Gestão \& Regionalidade, v. 32, n. 94, p.68-83, jan-abr/2016.

SANTOS, V. A. Q.; HOFFMANN, F. L. Avaliação das boas práticas de fabricação em linha de processamento de queijos Minas frescal e ricota. Revista do Instituto

Adolfo Lutz, v. 69, n. 2, p. 222-228, 2010. 
SGARBI, J. et al. Agroindústria familiar rural: contribuições para o desenvolvimento agroecológico. 2007. Disponível em:

<http://www.bibliotecadigital.abong.org.br/bitstream/handle/11465/337/CAPA_agroi ndustria_familiar_rural.pdf?sequence=1>. Acesso em: 04 set. 2017.

SIMIONI, F. J.; HOFF, D. N.; SILVA, C. Diversificação e atividades não agrícolas como alternativas de renda na agricultura familiar: um estudo de caso no município de painel/sc. Revista Brasileira de Gestão e Desenvolvimento Regional, v. 12, n. 2, p. 185-207, mai-ago/2016.

THOMÉ, B. R., et al. Gestão da qualidade nas agroindústrias de suínos de Francisco Beltrão-Paraná. Revista Espacios, v.38, n. 21, p. 9, 2017.

ZUIN, L. F. S.; ZUIN, P. B. Produção de alimentos tradicionais contribuindo para o desenvolvimento local/regional e dos pequenos produtores rurais. Revista Brasileira de Gestão e Desenvolvimento Regional, v. 4, n. 1, p.109-127, jan-abr/2008.

Claudia Maria Prudêncio de Mera. Universidade de Cruz Alta - Cruz Alta - RS Brasil.cmera@unicruz.edu.br

Thomas Rosa Menegazzi. Universidade de Cruz Alta - Cruz Alta - RS - Brasil. thomasmenegazzi@hotmail.com

Jorge Stumpfs Diaz. Universidade de Cruz Alta - Cruz Alta - RS - Brasil. orgediaz@hotmail.com

Como citar: PRUDÊNCIO DE MERA, Claudia Maria; MENEGAZZI, Thomas Rosa; DIAZ, Jorge Stumpfs. Análise da conformidade higiênico-sanitária de unidades agroindustriais familiares produtoras de derivados lácteos em municípios do Rio Grande do Sul. Redes (St. Cruz Sul, Online), Santa Cruz do Sul, v. 25, n. 2, p. 832-856, abr. 2020. ISSN 1982-6745. Disponível em: https://online.unisc.br/seer/index.php/redes/article/view/13551 Acesso em: 15 maio 2020. doi: https://doi.org/10.17058/redes.v25i2.13551

\section{CONTRIBUIÇÃO DE CADA AUTOR}

a. Fundamentação teórico-conceitual e problematização: Cláudia, Jorge e Thomas

b. Pesquisa de dados e análise estatística: a coleta de dados secundários: Thomas

c. Elaboração de figuras e tabelas: Thomas

d. Fotos: não se aplica

e. Elaboração e redação do texto: Cláudia, Jorge e Thomas

f. Seleção das referências bibliográficas: Cláudia, Jorge e Thomas

Fontes de financiamento: a pesquisa foi realizada com recursos próprios dos pesquisadores. 